\title{
Curcumin: Its Bioavailability and Nanoparticle Formulation: A Review
}

\author{
Ankita Dutta' ${ }^{1}$ R. K. Patil ${ }^{2}$, H. C. Patil ${ }^{3}$ \\ ${ }^{1}$ Pharm. D (Student), Adesh Institute of Pharmacy and Biomedical Sciences, Adesh University, Bathinda \\ ${ }^{2}$ Professor, Department of Pharmacy Practice, Adesh Institute of Pharmacy \& Biomedical Sciences, \\ Adesh University, Bathinda \\ ${ }^{3}$ Professor \& Principal, Department of Pharmacy Practice, Adesh Institute of Pharmacy \& Biomedical Sciences, \\ Adesh University, Bathinda \\ Corresponding Author: R. K. Patil
}

\begin{abstract}
Curcumin is used as traditional Indian and Chinese medicine in order to treat various diseases as well as used as a wound healing agent. Two to five percent in turmeric is curcumin; turmeric is available in yellow colour mainly obtained from polyphenolic pigment and fat-soluble substance called as curcuminoids, mostly used in the Indian subcontinent. Various clinical trials are conducted for understanding the wide range of therapeutic uses of curcumin. According to the studies, it shows that curcumin manifests very poor oral bioavailability, and forms numerous curcumin metabolites are formed after metabolism, although the bioavailability is low but the therapeutic activity of the curcumin for the various diseases, and for treatment of the disease enhancement of bioavailability of the curcumin in the future is necessary. According to the recent study on nanocurcumin with the size less than $100 \mathrm{~nm}$ which is an application of polymer-based nanoparticle of curcumin. It was observed that this polymer-based nanoparticle of curcumin has similar in vitro activity as that of free curcumin in pancreatic cell lines. In in-vivo study performed with the healthy volunteers a cream containing curcuminoid loaded SLNs was topically applied over the cream containing free curcuminoid showed the improvement in efficacy. Therefore, various techniques are developing for the nanoparticulate formulations.
\end{abstract}

Keywords- Curcuminoids, bioavailability, nanoparticulate, nanocurcumin, polyphenolic.

\section{INTRODUCTION}

Curcumin is the yellow polyphenolic compound extracted from the rhizome (2) of curcuma longa belong to the ginger family of Zingiberaceae, also known as diferuloylmethane $\left(\mathrm{C}_{21} \mathrm{H}_{20} \mathrm{O}_{6}\right)$ stems of rhizomes which are horizontally underground, turmeric is available in yellow colour mainly obtained from polyphenolic pigment and fat-soluble substance called as curcuminoids.(1), mostly used in the Indian subcontinent as spice and food colouring material (5) the mostly active compound in turmeric is curcuminoids, another type of curcuminoid are also available names as bisdemethoxycurcumin demethoxycurcumin. Polyphenols and curcuminoids are major for forming yellow turmeric colour, enol and keto are tautomeric forms of turmeric. (3)

Two to five percent in turmeric is curcumin. Approximately the preparations of curcumin consist of $77 \%$ diferuloylmethane, $18 \%$ demethoxycurcumin, and 5\% bisdemethoxycurcumin. Curcumin is hydrophobic in nature and has $420 \mathrm{~nm}$ of absorption maxima and gets dissolved indimethylsulfoxide, acetone, ethanol, and oils. The presence of acids causes the colour of the curcumin to change from yellow to deep and this form is used in the religious ceremonies. (4) 
Curcumin was isolated in 1815 from turmeric and in 1910 the structure was identified as diferuloylmethane (4) In Southeast Asia and tropical countries turmeric grows naturally and used for many purposes. Since 19,00 BCE curcuma longa has been used as a part of Indian Ayurvedic medicine use of turmeric was restrain to the Asia until the 12th-13th centuries AD (7) but now a time it has been used as pigment, spice, food colouring, additive and also for medical purpose. Therefore, turmeric has reached in clinical phase I and II just in last 12-15 years. In Southeast Asia curcumin is used as alternative of medicine compound, jaundice, allergy, wounds, sprains, skin infection and many more. (2)Various clinical trials are conducted for understanding the wide range of therapeutic uses of curcumin. (6) During the last decades it was observed in the research that was taking place on antioxidant property of curcumin and the potential property of curcumin was determined. (5),(32)

When curcumin is orally administered, after that it metabolise is into curcumin glucuronide and curcuminsulfonate. However, when curcumin is administered systemically or intraperitoneally, it is metabolized into tetrahydrocurcumin, hexhyrdrocurcumin, and hexhydrocurcuminol. (4)

There are various effect of curcumin on the target cells, Curcumin can modulate numerous different transcription factors, cytokines, growth factors, kinases, and other enzymes (4),(34)

Turmeric consists of 3 curcuminoids:

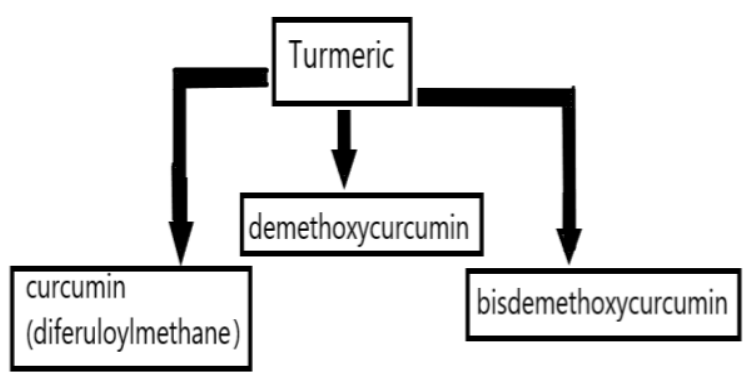

Curcumin is used as traditional Indian and Chinese medicine in order to treat various diseases as well as used as a wound healing agent. Currently, numerous researches on curcumin proved that this agent can prevent the proliferation of cancer cells and acts as a cell death inducer by inducing many signalling pathways. Therefore, as an inducer of cell death curcumin has become a chemopreventive and anti-cancer agent. This can be proved by performing various in vitro experiments and preclinical studies on the animal models. (14)

\section{Properties and medicinal use of curcumin:}

- Curcumin has antioxidant, antiinflammatory, antiviral and antifungal actions. (7)

- Curcumin have anti-inflammatory activity by inhibition the molecules, which play an important role in case of inflammation. (2)

- Turmeric is effective in reducing postsurgical inflammation. (3)

- Curcumin is also responsible for reducing LDL and increasing HDL, inhibiting platelet aggregation and inflammatory response that reduce the occurrence of myocardial infarction and cardiovascular diseases. (8)

- Curcumin having antifungal, antiviral, anti-inflammatory, antioxidant, neuroprotective, anti-rheumatoid arthritis, anti-osteoarthritis activity.

- Curcumin shows activity against inflammatory bowel disease, arthritis, colitis, gastritis and fever by suppressing the inflammatory markers. (4)

- Turmeric prevent the Growth of H.pylori, which is the main reason for gastric ulcer and linked with cancer of gastric.

- Curcumin acts as a hepatoprotective agent preventing liver fibrosis, it is also considered as an antifibrotic compound. (8) 
- Curcumin leads to development of resistance to insulin in patients with diabetes mellitus II. (4)

- Toxicity of heavy metal can be prevented by binding of lead and cadmium with curcumin, it is having protective action towards brain.

- By topical administration of curcumin, anti-psoriatic activity can be observed(8)
- Curcuma longa act as inhibitor of glutathione S-transferase, cyclooxygenase and 5-lipoxygenase.

- It is also responsible for improving digestion by increasing the amount of bile from the gall bladder. (8)

\section{Various properties of curcumin can be classified as}

\begin{tabular}{|c|c|}
\hline \multicolumn{2}{|l|}{ Chemical properties: } \\
\hline \begin{tabular}{|l|} 
Solubility \\
\end{tabular} & Soluble in acetone, ethanol, dimethylsulphoxide and is insoluble in water. (3) \\
\hline Melting point & $183^{\circ} \mathrm{c}(3)$ \\
\hline Molecular weight & 368.37 \\
\hline pH & $\begin{array}{l}\text { At } \mathrm{pH} 3-7 \\
\text { Curcumin acts as } \mathrm{H} \text { - atom donor } \\
\text { Above } \mathrm{pH} 7 \\
\text { Curcumin's hue is red } \\
\text { Above } \mathrm{pH} 8 \\
\text { Curcumin acts as electron donor (3) }\end{array}$ \\
\hline
\end{tabular}

In curcumin the pharmacokinetics property is usually studied in animals, then in humans, that are reviewed. According to the studies, it shows that curcumin manifests very poor oral bioavailability, and forms numerous curcumin metabolites are formed after metabolism like- curcumin glucuronide, curcumin sulfate, hexahydrocurcumin, tetrahydrocurcumin, and dihydrocurcumin. In recent years, several derivatives, analogs and drug vehicle combinations of curcumin were developed by various experimental studies, these experimental outcomes helped in improving absorption and enhancing the systemic bioavailability than the parent drug curcumin. (29)

Pharmacokinetic properties
\begin{tabular}{|l|l|}
\hline Pre- clinical pharmacokinetics & \\
\hline Oral bioavailability & Low \\
\hline Administration & Orally, intravenous, intraperitoneal. \\
\hline Metabolism & Intestine; rapid first pass metabolism \\
\hline Excretion & In bile (3) \\
\hline Clinical pharmacokinetics & \\
\hline Bioavailability & Low \\
\hline Distribution & Low distribution in hepatic tissue and in other tissues \\
\hline Metabolism & Efficient first pass metabolism; Intestinal \\
\hline
\end{tabular}

According to some of experiments the effect of pharmacokinetic parameters of curcumin of a mixture of curcumin with phosphatidylcholine (CU-PC). By using the intestine sac technique in the ex vivo studies indicated that the mixture of CU-PC showed more absorption than using curcumin only.
By using isolated hepatocytes of rats in, In vivo studies and in vitro studies in rats manifests that utilizing CU-PC leads to improvement bioavailability and pharmacokinetics, this enhance the hepatoprotective activity as compared to curcumin alone. (29) 


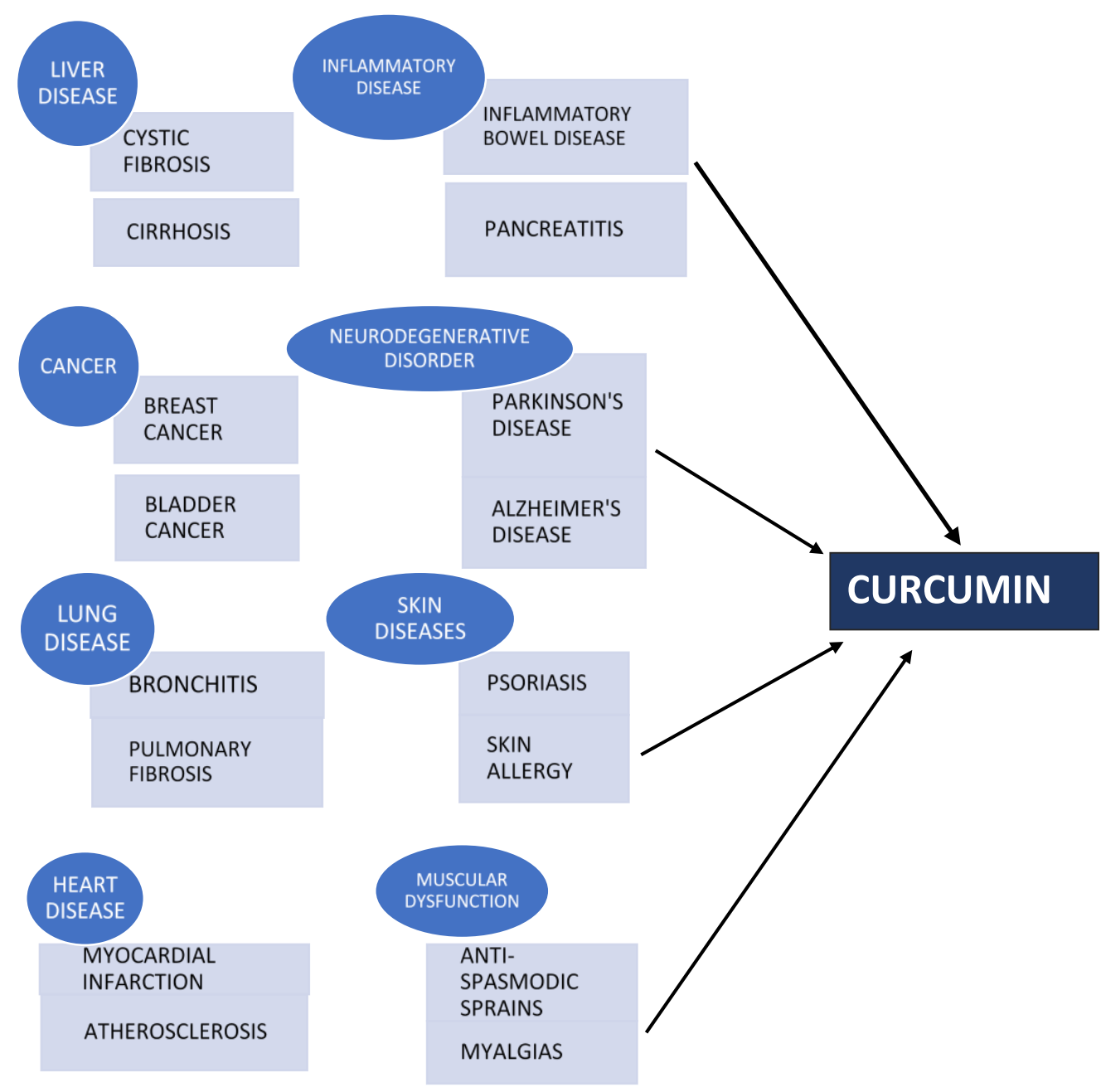

Figure 1: Uses of curcumin in various diseases

As the previous study provides curcumin having low bioavailability, various approaches are used to enhance the bioavailability, by using curcumin nanoparticles, liposomal curcumin and piperine is used as adjuvant. Bioavailability enhanced of curcumin is effective against arthritis, Crohn's disease, diabetes, neurological disease and cancer.

\section{Problems of Curcumin Bioavailability:}

There are several factors which affect the bioavailability of any agent like high rate of absorption, low intrinsic activity clearance and fast elimination from the body, low serum level, short half- life, apparent rapid metabolism, and limited tissue distribution.

According to the study which was conducted on the cancer patients mainly on pharmacokinetics, metabolites, and systemic bioavailability of curcumin. A phase I clinical trial was conducted on 25 patients, these patients have several precancerous lesions, oral doses of $4 \mathrm{~g}, 6 \mathrm{~g}$ and $8 \mathrm{~g}$ of curcumin was daily administered for three months identification of concentrations of serum curcumin shows that absorption of curcumin is low and system in bioavailability of curcumin is limited. After the dose of curcumin levels in serum increases in 1 to $2 \mathrm{hrs}$ but then decreases rapidly. Although metabolites of curcumin and excretion of curcumin was not identified in the study. (6)

In the phase I of clinical trials, high dose of curcumin that is $12 \mathrm{~g} /$ day is proven safe for use in humans but the bioavailability that is exhibited is poor. Due to poor absorption, rapid systemic elimination and rapid metabolism the 
plasma level and tissue levels of the curcumin is low.

Various approaches have been taken place for the improvement in the bioavailability of curcumin. These approaches include:
- Use of adjuvant like piperine that interferes with glucuronidation

- Use of liposomal curcumin

- Curcumin nanoparticles

- Use of curcumin phospholipid complex

- Use of structural analogues of curcumin (e.g., EF-24).

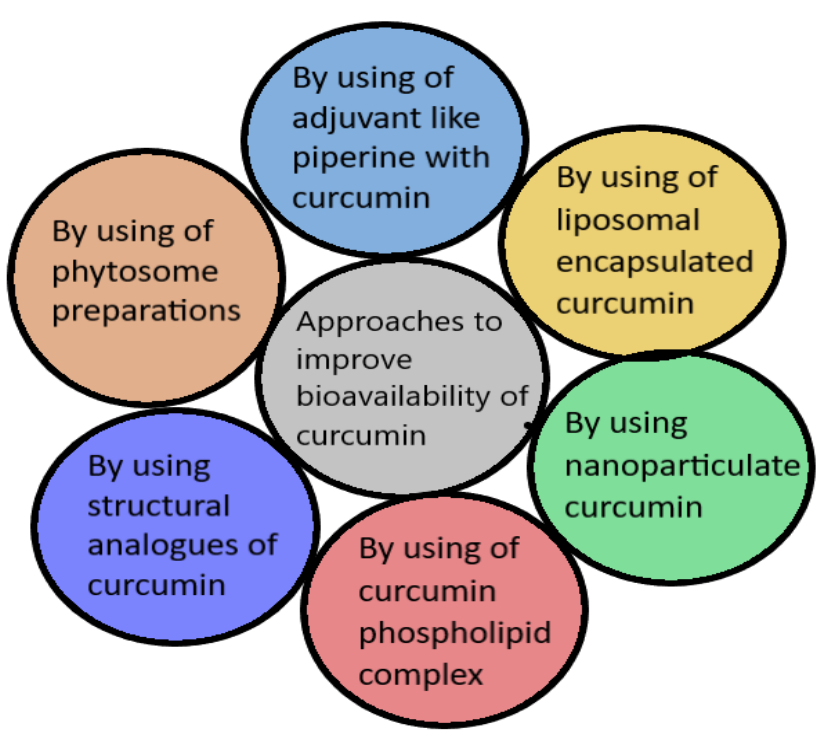

Figure 2: Various approaches to improve bioavailability.

Due to the approaches it has been reported to have rapid absorption with a peak plasma half-life. Although the bioavailability is low but the therapeutic activity of the curcumin for the various diseases, like cancer, cardiovascular diseases, diabetes, arthritis, neurological diseases and Crohn's disease etc. And for treatment of the disease enhancement of bioavailability of the curcumin in the future is necessary. (11)

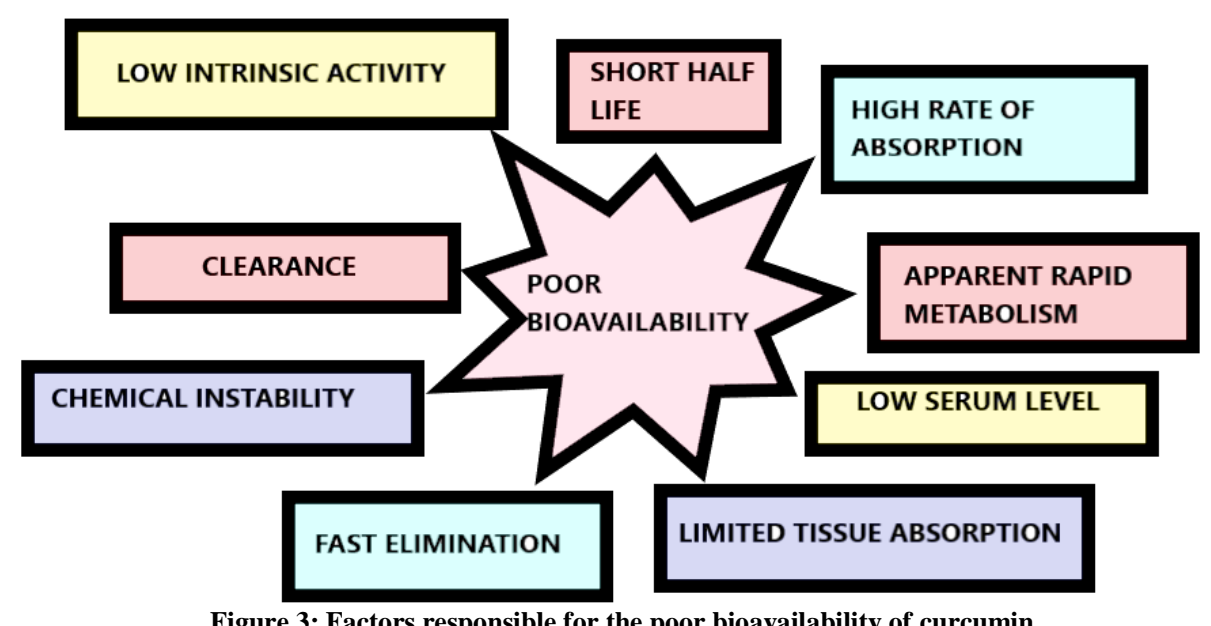

Figure 3: Factors responsible for the poor bioavailability of curcumin

Improvement of bioavailability of curcumin

1. To improve water solubility and bioavailability,
Encapsulation of curcumin was done by liposomes and then they were further coated with thiolated chitosan and formation of liposomal hydrogels takes place. These 
hydrogels are liquid in room temperature and can be injected in-situ.

Evaluation: By performing the cytotoxicity test specifies that the cytocompatibility of the liposomal hydrogels is good, but after 72 hrs the MCF-7 cells were suppressed and killed after the encapsulation of curcumin with liposomes. The in vivo breast cancer recurrence experiment showed that the curcumin-liposome gel inhibited breast cancer recurrence after tumors were resected, and the tissue of defect in the CSSH/Cur-Lip gel group was repaired.

Results: According to the above study which proves that the drug-loaded liposomal hydrogels can deliver curcumin continuously and exerted an excellent tumoricidal effect in vitro and in vivo. The injectable, in situ-formable, and thermosensitive CSSH/Cur-Lip gel can be designed as a promising novel drug delivery vehicle to be used as carriers for local accurate and sustained drug delivery to minimize burst release and as tissue engineering scaffolds for tissue regeneration after tumor resection. (12)

\section{According to the test performed in the rats with both the preparations phytosome and non-phytosome curcumin extract the bioavailability of the curcumin is determined. \\ Study:}

For overnight the rats were kept on fasting, then the rats administer by mouth the phytosomal or the non-phytosomal preparation. Then after oral gavage,the blood samples were collected at particular interval of time $15,30,60$, or 120 minutes. By oral gavage at $360 \mathrm{mg} / \mathrm{kg}$ body weight curcumin complex was administered, in either phytosome or non-phytosome preparation. (16)

\begin{tabular}{|l|l|}
\hline Phytosome preparation & Non -phytosomal preparation \\
\hline Result: & Result: \\
According to the study, in the collected blood samples of rats, Curcumin I along with its & $\begin{array}{l}\text { According to the study in non- } \\
\text { phytosomal preparations, the plasma } \\
\text { metabolite's curcumin glucuronide, curcumin sulfate, tetrahydrocurcumin, and hexahydrocurcumin } \\
\text { was identified. In this study the plasma absorption of curcumin of the phytosome preparation } \\
\text { abowed superior from the first } 30 \text { minutes for the period 0-120 minutes andfor the curcumin } \\
\text { phytosome phytosomal preparation. } \\
\text { the AUC values were 5.6 times better. }\end{array}$ \\
Curcumin I was accumulated in the liver in the phytosome preparation. (16) & was lower in this preparation. (16) \\
\hline
\end{tabular}

3. The study of assessing of bioavailability of modulated curcumin in the liver and small intestine.

Study: A total of ten healthy volunteers were orally administered curcumin of 2000 mg with $20 \mathrm{mg}$ of piperine and without 20 $\mathrm{mg}$ of piperine randomly in controlled manner to the volunteers. (13)

\begin{tabular}{|l|l|}
\hline Dose of curcumin with piperine & Dose of curcumin without piperine \\
\hline $\begin{array}{l}\text { Result: When curcumin is administered with piperine } \\
\text { in combination, the bioavailability increases to } 2000 \% .\end{array}$ & $\begin{array}{l}\text { Result: When only curcumin is administered to the volunteers the increase in the } \\
\text { bioavailability is much lower as compared with the combination of curcumin and }\end{array}$
\end{tabular}

$\begin{array}{ll}\text { Result: When curcumin is administered with piperine } & \text { Result: When only curcumin is administered to the volunteers the increase in the } \\ \text { in combination, the bioavailability increases to } 2000 \% & \text { bioavailability is much lower as compared with the combination of curcumin and }\end{array}$ piperine.

\section{Study:}

Turmeric is a natural product extracted from plants play a major role in healthcare services and in many cultures, both ancient and modern. Chemical constituent of turmeric -curcumin with anticancer activity but with poor solubility of water that limits the clinical activity.

Methods: A total of five series of poly (caprolactone)-poly (ethylene glycol)- poly (caprolactone) (PCL-PEG-PCL) triblock copolymers were synthesised. By using solvent evaporation method, the nanoparticles (NPs) were prepared. On the encapsulation of hydrophobic curcumin effect was assigned to the length of the copolymers' hydrophilic and hydrophobic chains to achieve the best delivery system.

Evaluation: By the HNMR, FT-IR, DSC, and GPC techniques the structure of the copolymers was characterized, entrapment efficiency and drug loading assignments was performed and the evaluation of the distribution of particle and by using the 
direct dispersion method in-vitro release was evaluated.

Results: In $\mathrm{NP}_{4}$ has $71 \%$ and in $\mathrm{NP}_{5}$ has $83 \%$ of efficiency in biodegradable nanoparticulate formulations in which curcumin was encapsulated. The particle diameter in NP4 is $112 \mathrm{~nm}$ and in NP5 is $110 \mathrm{~nm}$ measured by the Dynamic laser light scattering (DLS). According to the in vitro release experiments NP5 showed the effective controlled the release of curcumin, in 120 hours only $51 \%$ of curcumin was released and these leads to the enhancement of the bioavailability and water solubility of curcumin.

Conclusions: According to the results which indicate that the formulation of curcumin-loaded PCL-PEG-PCL nanoparticles were successful in the improvement of water solubility of curcumin, which shows that it has potential application in cancer treatment. (33)

\section{Strategies of nanoparticle formulation of curcumin}

The main purpose of choosing nanoparticles as drug delivery system so that the surface properties, size of particles and the release of pharmacologically active agents can be managed to attain the sitespecific action of the drug at optimal therapeutic rate and dosage regimen. In curcumin which is having low aqueous solubility like in hydrophobic agents, nanoparticle-based delivery systems are used.

According to the recent study on nanocurcumin with the size less than 100 $\mathrm{nm}$ which is an application of polymerbased nanoparticle of curcumin. It was observed that this polymer-based nanoparticle of curcumin has similar in vitro activity as that of free curcumin in pancreatic cell lines.

In in-vivo study performed with the healthy volunteers a cream containing curcuminoid loaded SLNs was topically applied over the cream containing free curcuminoid showed the improvement in efficacy. Therefore, various techniques are developing for the nanoparticulate formulations.(22)

\begin{tabular}{|c|c|c|c|c|}
\hline Formulation & & \multicolumn{2}{|c|}{ Evaluation } \\
\hline $\begin{array}{l}\text { 1.A novel } \\
\text { nanoparticle } \\
\text { (CURN) }\end{array}$ & \multicolumn{2}{|c|}{$\begin{array}{l}\text { By nanoprecipitation method } \\
\text { Curcumin of } 50 \mathrm{mg} \text { was solubilized in } 25 \mathrm{~mL} \text { of ethanol. } \\
\text { The solutions in organic phase were quickly injected into } 75 \mathrm{~mL} \text { of an } \\
\text { aqueous solution that containing } 300 \mathrm{mg} \text { of PVP. } \\
\text { During the injection process, at } 22000 \mathrm{rpm} \text { for } 25 \text { min homogenization of } \\
\text { the mixed solution takes place. } \\
\text { By rotary vacuum evaporation at } 40 \mathrm{oc} \text { in a water bath excessive amount of } \\
\text { ethanol is removed from the mixed solution. } \\
\text { Approximately, } 70 \mathrm{~mL} \text { left over fraction, comprising of the nanoparticle } \\
\text { solution, was the used for the further particle size analysis and stored in a } \\
\text { moisture proof instrument for successive characterizations (7) }\end{array}$} & \multicolumn{2}{|c|}{ 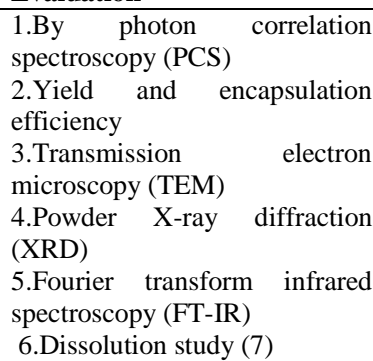 } \\
\hline \multicolumn{5}{|c|}{ Result: The use of nanoparticle helped in Cell proliferation assay, clonogenic assay, flow cytometry analysis etc. (7) } \\
\hline \multicolumn{2}{|l|}{ Formulation } & \multicolumn{2}{|l|}{ Preparation } & Evaluation \\
\hline \multicolumn{2}{|c|}{$\begin{array}{l}\text { 2.NanoCurcTM -The predistilled } \\
\text { monomers of NIPAAM, VP and AA are } \\
\text { mixed together in a molar ratio of } \\
60: 20: 20 \text {, respectively. }\end{array}$} & \multicolumn{2}{|l|}{$\begin{array}{l}\text { Polymerization was performed for } 24 \text { hours at } 30^{\circ} \mathrm{C} \text { under an } \\
\text { inert gas nitrogen atmosphere, using APS and FeSO } 4 \text { as initiator } \\
\text { and activator, respectively. } \\
\text { After complete polymerization, the total aqueous solution of } \\
\text { polymer was purified using dialysis, and then lyophilized for post } \\
\text { loading of curcumin, } \\
\text { Then a stock solution of } 10 \mathrm{ml} \text { and polymeric nanoparticles of } \\
100 \mathrm{mg} \text { was mixed slowly with } 150 \mu \mathrm{l} \text { of curcumin solution in } \\
\text { chloroform } 10 \mathrm{mg} / \mathrm{ml} \text {, and for } 15-20 \text { minutes firmly stirred on } \\
\text { low heating, in order to evaporate chloroform and load curcumin } \\
\text { simultaneously. } \\
\text { The resulting solution, of } 1.5 \% \text { (w/w) loaded with the curcumin } \\
\text { in nanoparticles, was then lyophilized and frozen on a dry ice or } \\
\text { acetone bath. } \\
\text { The nanocurcumin powder which is lyophilized is stored at } 4{ }^{\circ} \mathrm{C} \\
\text { until further use. (1) }\end{array}$} & $\begin{array}{l}\text { 1.By Cell proliferation } \\
\text { assay } \\
\text { 2.Apoptosis assay } \\
\text { 3.Cell lines and cultures } \\
\text { 4.Cell cycle analysis } \\
\text { 5.Protein analysis } \\
\text { 6.Clonogenic assay } \\
\text { 7.Flow cytometry } \\
\text { analysis PCR } \\
\text { Quantitative } \\
\text { analysis (1) }\end{array}$ \\
\hline
\end{tabular}




\begin{tabular}{|c|c|c|}
\hline Formulation & Preparation & Evaluation \\
\hline $\begin{array}{l}\text { 3.Load CUR } \\
\text { into the } \\
\text { functionalized } \\
\text { surface } \\
\text { of the pores } \\
\text { of nanocarrier }\end{array}$ & $\begin{array}{l}\text { Dropwise addition of the curcumin solution in acetone to a } 5 \\
\text { mg of guanidine functionalized pegylated KIT-6 which was } \\
\text { kept for } 24 \mathrm{~h} \text { under inert atmosphere. } \\
\text { At } 15,000 \mathrm{rpm} \text {, the Solid sample was centrifuged for } 5 \mathrm{~min} \text {. } \\
\text { The collected solid sample was then washed with } 30 \mathrm{ml} \text { of } \\
\text { ethyl alcohol so that extra curcumin is rinsed away. } \\
\text { This is then dried under vacuum to get the loaded curcumin. }\end{array}$ & $\begin{array}{l}\text { To evaluate the CUR-loading efficiency, the supernatant } \\
\text { and washed solutions were collected and the residual } \\
\text { CUR content was measured by using UVevis } \\
\text { measurement( } 9 \text { ) }\end{array}$ \\
\hline
\end{tabular}

\begin{tabular}{|c|c|c|}
\hline Formulation & Preparation & Evaluation \\
\hline $\begin{array}{l}\text { 4.To evaluate the anticancer } \\
\text { potential of curcumin within } \\
\text { BCD-C complexes and } \\
\text { liposomes, cell proliferation } \\
\text { assays were performed using } \\
\text { lung and colon cancer cell lines }\end{array}$ & $\begin{array}{l}\text { At } 37^{\circ} \mathrm{c} \text { temperature in } 5 \% \text { of } \mathrm{CO} 210,000 \text { cells per well are grown and seeded in } 96- \\
\text { well plates. } \\
\text { For } 24 \mathrm{hrs} \text { the cells were attached before removing from the media the cells were then } \\
\text { ready for the formulations. } \\
\text { The samples were then added that were curcumin entrapped liposomes, } \beta C D-C \\
\text { complex-entrapped liposomes, curcumin, } \beta C D-C \text { complexes, PBS, } 0.25 \% \text { DMSO and } \\
\beta C D \text {, all this was prepared in PBS (except the curcumin dissolved in } 0.25 \% \text { DMSO) } \\
\text { For } 48 \text { hrs the cells were incubated and a MTT (3-(4,5-Dimethylthiazol-2-yl)- } \\
2,5 \text { diphenyltetrazolium bromide) cell viability assay was performed. } \\
\text { Amount of PBS, DMSO and } \beta C D \text { were used as controls. As a percentage of cell growth, } \\
\text { the calculation of the antiproliferative activity was done. And lastly, values of EC50 of } \\
\text { each formulation was estimated by interpolating from the graph. (10) }\end{array}$ & $\begin{array}{l}\text { 1.Cell } \\
\text { viability } \\
\text { assay }\end{array}$ \\
\hline \multicolumn{3}{|c|}{$\begin{array}{l}\text { Result: The median effective dose (EC50) of the formulations on colon cancer cells were calculated to be } 0.96 \mu \mathrm{M} \text { for curcumin-entrapped } \\
\text { liposomes, } 1.9 \mu \mathrm{M} \text { for curcumin, } 2.95 \mu \mathrm{M} \text { for } \beta \mathrm{CD}-\mathrm{C} \text { complexes and } 3.25 \mu \mathrm{M} \text { for liposomes containing } \beta C D-\mathrm{C} \text {. } \\
\text { The EC } 50 \text { of the formulations on lung cancer cells followed the same pattern, being } 0.90 \mu \mathrm{M} \text { for curcumin-entrapped liposomes, } 1.5 \mu \mathrm{M} \text { for } \\
\text { curcumin, } 2.4 \mu \mathrm{M} \text { for } \beta \mathrm{CD}-\mathrm{C} \text { and } 2.9 \mu \mathrm{M} \text { for liposomes containing } \beta \mathrm{CD} \text {-C. } \\
\text { liposomal formulations containing native curcumin the most effective in preventing cell proliferation. However, all curcumin-containing } \\
\text { formulations appeared to be effective in inhibiting cell proliferation. (10) }\end{array}$} \\
\hline
\end{tabular}

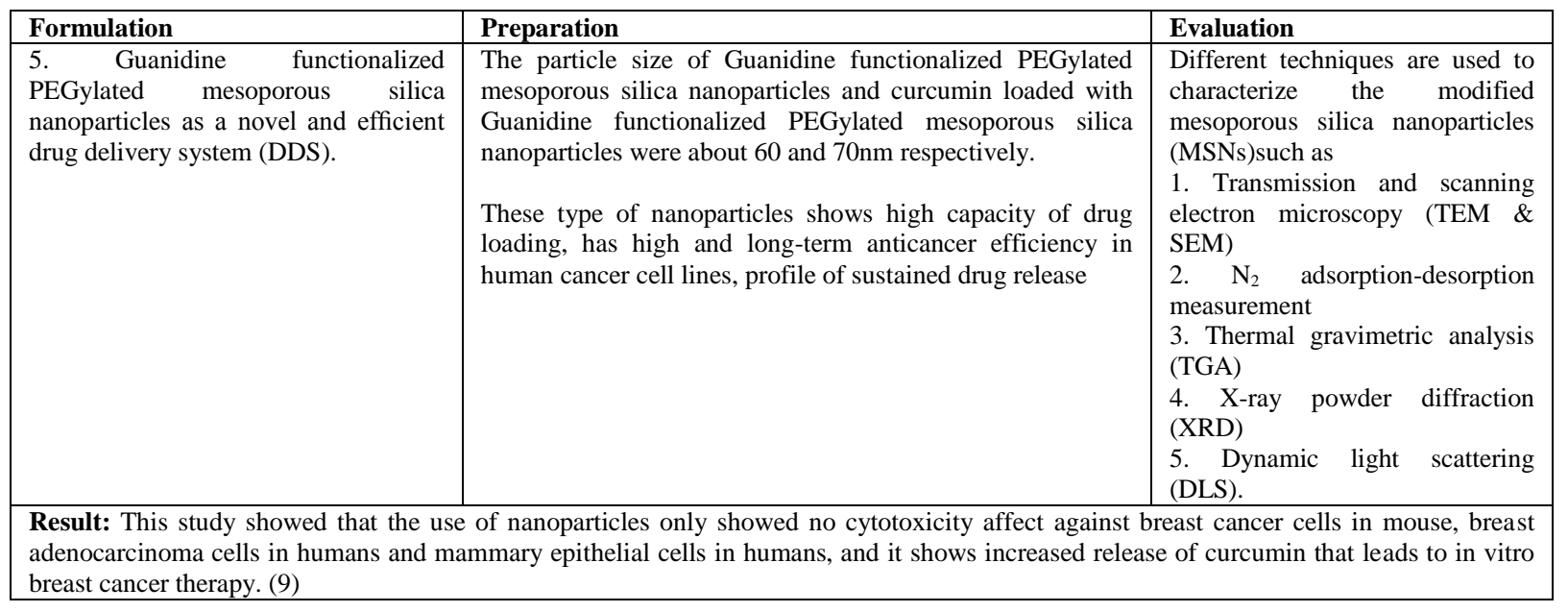

\section{Studies of the evaluation of in- vitro characteristics and in-vivo characteristics of curcumin nanoparticulate formulation.} 1. Study: To fabricate biodegradable nanoparticle formulation of bisdemethoxycurcumin analogue (BDMCA), a novel curcumin analogue, and evaluate its in vitro and in vivo characteristics.

Methods: Nanoparticle formulations were fabricated by a double emulsion solvent evaporation technique using polycaprolactone as the polymer. The nanoparticles were characterised for drug content, particles size, in vitro drug release and the drug-polymer interaction. The in vivo properties of the formulations in male Wistar rats were evaluated from the pharmacokinetics and pharmacodynamics of BDMCA following i.v. administration of the nanoparticles. BDMCA solution was administered i.v. as a reference, hepatoprotectivity of the formulation was determined in a $\mathrm{CCl} 4$-treated rat model.

Results: The BDMCA nanoparticles were successfully prepared using double emulsion solvent evaporation technique. The nanoparticle formulations effectively sustained the release of the drug for more than 10 days both in vitro and in vivo. They also offered better pharmacokinetic 
properties to the drug than that afforded by the free drug itself. Intravenous nanoparticular administration reversed serum liver enzyme levels by $90 \%$, compared to $52 \%$ for repeated i.v. administration of the solution form.

Conclusion: BDMCA particle demonstrated good pharmacokinetic and pharmacodynamic properties following i.v. administration. (21)

2. Study: In Vivo Kinetic Study of the TPGS-Stabilized Curcumin Nanoparticle after Oral Administration.

Method: Male Wistar rats of $200 \mathrm{~g}$ weight with an age of 2 months were used in this study. The animals were fasted for $12 \mathrm{~h}$ prior to the experiment but given free access for water ad libitum. Animals were divided into two groups of six rats each, and given TPGS-curcumin suspension or TPGSstabilized curcumin nanosuspension orally with the same dose of $10 \mathrm{mg} / \mathrm{kg} \mathrm{BW}$. Blood sampling of $500 \mu \mathrm{L}$ was performed through the tail vein at the interval times: $0 ; 0.25$; $0.5 ; 1 ; 2 ; 4 ; 8 ; 12$, and $24 \mathrm{~h}$ after oral administration. The blood samples were placed into heparinized tubes.

Evaluation: To obtain plasma, the heparinized blood samples were centrifuged at $12,500 \mathrm{rpm}$ for $5 \mathrm{~min}$. Curcumin in plasma samples were determined by the HPLC method. Prior to HPLC analysis, 200 $\mu \mathrm{L}$ of plasma was added with $80 \mu \mathrm{L}$ aquabidest, vortexed for $20 \mathrm{~s}$. Ethyl acetate of $480 \mu \mathrm{L}$ was further added to the plasmaaquabidest mixture, and againvortexedfor30s. Subsequently, the mixture was centrifuged at $13,000 \mathrm{rpm}$. The organic phase of $450 \mu \mathrm{L}$ was taken and vacuum-dried. Theresiduewasredissolvedin100 $\mu \mathrm{L}$ of mobile phase, vortexed for $30 \mathrm{~s}$, and was then ready for HPLC analysis.

In vivo parameters of curcumin were calculated using computer software multifit (26)

\section{CONCLUSION}

Curcumin is the yellow polyphenolic compound extracted from the rhizome of curcuma longa belong to the ginger family of Zingiberaceae, turmeric is available in yellow colour mainly obtained from polyphenolic pigment and fat-soluble substance called as curcuminoids. There are several factors which effect the bioavailability of curcumin, therefore various approaches have been taken place for the improvement in the bioavailability of curcumin that are- byencapsulating of curcumin by liposomes, by using solvent evaporation method, preparation of the nanoparticles, preparations phytosome and non-phytosome curcumin etc. Nanoparticles are selected as drug delivery system and various formulations are developed as invivo study performed with the healthy volunteers a cream containing curcuminoid loaded SLNs was topically applied over the cream containing free curcuminoid showed the improvement in efficacy. Various formulations are a novel curcumin nanoparticle system (CURN), Guanidine functionalized PEGylated mesoporous silica nanoparticles as a novel and efficient drug delivery system (DDS), Load CUR into the functionalized surface of the pores of nanocarrier, nanoCurcTM -The predistilled monomers of NIPAAM, VP and AA are prepared and evaluated which are beneficial in various purposes. Evaluation of in-vitro and in-vivo characteristics of curcumin nanoparticle formulation includes Biodegradable nanoparticle formulation of bis-demethoxycurcumin analogue and TPGS-Stabilized Curcumin Nanoparticle strategies which demonstrates good pharmacokinetic and pharmacodynamic properties following i.v. administration.

\section{Acknowledgement: None}

Conflict of Interest: None

Source of Funding: None 


\section{REFERENCES}

1. Lim KJ, Bisht S, Bar EE, Maitra A, Eberhart CG. A polymeric nanoparticle formulation of curcumin inhibits growth, clonogenicity and stem-like fraction in malignant brain tumors. Cancer biology \& therapy. 2011 Mar 1;11(5):464-73.

2. Bisht S, Feldmann G, Soni S, Ravi R, Karikar C, Maitra A, Maitra A. Polymeric nanoparticle-encapsulated curcumin (" nanocurcumin"): a novel strategy for human cancer therapy. Journal of nanobiotechnology. 2007 Dec;5(1):1-8.

3. Sharma RA. G escher AJ, S teward WP. 2 005. Curcumin: the story so far. Eur. J. Cancer. 1955;41:1955-68.

4. Sankireddy S, Mittal S, Vinayak V. Curcumin-a Solid Gold in Medicine and Dentistry. Indian Journal of Public Health Research \& Development. 2015 Jul 1;6(3).

5. Jurenka JS. Anti-inflammatory properties of curcumin, a major constituent of Curcuma longa: a review of preclinical and clinical research. Alternative medicine review. 2009 Jun 1;14(2).

6. Yen FL, Wu TH, Tzeng CW, Lin LT, Lin CC. Curcumin nanoparticles improve the physicochemical properties of curcumin and effectively enhance its antioxidant and antihepatoma activities. Journal of agricultural and food chemistry. 2010 Jun 23;58(12):7376-82.

7. Aggarwal BB, Surh YJ, Shishodia S, editors. The molecular targets and therapeutic uses of curcumin in health and disease. Springer Science \& Business Media; 2007 Aug 6.

8. Ma'mani L, Nikzad S, Kheiri-Manjili H, AlMusawi S, Saeedi M, Askarlou S, Foroumadi A, Shafiee A. Curcumin-loaded guanidine functionalized PEGylated I3ad mesoporous silica nanoparticles KIT-6: Practical strategy for the breast cancer therapy. European journal of medicinal chemistry. 2014 Aug 18;83:646-54.

9. Rahman S, Cao S, Steadman KJ, Wei M, Parekh HS. Native and $\beta$-cyclodextrinenclosed curcumin: entrapment within liposomes and their in vitro cytotoxicity in lung and colon cancer. Drug delivery. 2012 Oct 1;19(7):346-53.

10. Udompornmongkol $\mathrm{P}$, Chiang $\mathrm{BH}$. Curcumin-loaded polymeric nanoparticles for enhanced anti-colorectal cancer applications. Journal of biomaterials applications. 2015 Nov;30(5):537-46.

11. Johnson JJ, Mukhtar H. Curcumin for chemoprevention of colon cancer. Cancer letters. 2007 Oct 8;255(2):170-81.

12. Sikora E, Scapagnini G, Barbagallo $M$. Curcumin, inflammation, ageing and agerelated diseases. Immunity \& Ageing. 2010 Dec;7(1):1-4.

13. Lopresti AL. The problem of curcumin and its bioavailability: could its gastrointestinal influence contribute to its overall healthenhancing effects?. Advances in Nutrition. 2018 Jan 1;9(1):41-50.

14. Kidd PM. Bioavailability and activity of phytosome complexes from botanical polyphenols: the silymarin, curcumin, green tea, and grape seed extracts. Altern Med Rev. 2009 Sep 1;14(3):226-46.

15. Sharma RA, McLelland HR, Hill KA et al. Pharmacodynamic and pharmacokinetic study of oral Curcuma extract in patients with colorectal cancer. Clin Cancer Res. $2001 \mathrm{Jul} ; 7(7)$ :1894-900.

16. Takahashi M, Uechi S, Takara K, Asikin Y, Wada K. Evaluation of an oral carrier system in rats: bioavailability and antioxidant properties of liposomeencapsulated curcumin. Journal of agricultural and food chemistry. 2009 Oct 14;57(19):9141-6.

17. Chattopadhyay I, Biswas K, Bandyopadhyay U, Banerjee RK. Turmeric and curcumin: Biological actions and medicinal applications. Current science. 2004 Jul 10:44-53.

18. Nguyen HN, Ha PT, Sao Nguyen A, Nguyen DT, Do HD, Thi QN, Thi MN. Curcumin as fluorescent probe for directly monitoring in vitro uptake of curcumin combined paclitaxel loaded PLA-TPGS nanoparticles. Advances in Natural Sciences: Nanoscience and Nanotechnology. 2016 Mar 30;7(2):025001.

19. Anuradha CA, Aukunuru J. Preparation, characterisation and in vivo evaluation of bis-demethoxycurcumin analogue (BDMCA) nanoparticles. Tropical Journal of Pharmaceutical Research. 2010;9(1).

20. Chauhan M, Saha S, Roy A. Curcumin: a review. Journal of Applied Pharmaceutical Research. 2014 Feb 15;2(1):18-28.

21. Ak T, Gülçin İ. Antioxidant and radical scavenging properties of curcumin. 
Chemico-biological interactions. $2008 \mathrm{Jul}$ 10;174(1):27-37.

22. Singh RK, Rai D, Yadav D, Bhargava A, Balzarini J, De Clercq E. Synthesis, antibacterial and antiviral properties of curcumin bioconjugates bearing dipeptide, fatty acids and folic acid. European journal of medicinal chemistry. 2010 Mar 1;45(3):1078-86.

23. Rachmawati H, Yanda YL, Rahma A, Mase N. Curcumin-loaded PLA nanoparticles: formulation and physical evaluation. Scientiapharmaceutica. 2016 Mar;84(1): 191-202.

24. Rachmawati H, Pradana AT, Safitri D, Adnyana IK. Multiple functions of $D-\alpha-$ tocopherol polyethylene glycol 1000 succinate (TPGS) as curcumin nanoparticle stabilizer: in vivo kinetic profile and antiulcerative colitis analysis in animal model. Pharmaceutics. 2017 Sep;9(3):24.

25. Chen YN, Hsu SL, Liao MY, Liu YT, Lai $\mathrm{CH}$, Chen JF, Nguyen MH, Su YH, Chen ST, Wu LC. Ameliorative effect of curcumin-encapsulated hyaluronic acidPLA nanoparticles on thioacetamideinduced murine hepatic fibrosis. International journal of environmental research and public health. 2017 Jan;14(1):11.

26. Basnet P, Hussain H, Tho I, Skalko-Basnet N. Liposomal delivery system enhances anti-inflammatory properties of curcumin. Journal of pharmaceutical sciences. 2012 Feb 1;101(2):598-609.

27. Beevers CS, Huang S. Pharmacological and clinical properties of curcumin. Botanics: Targets and Therapy. 2011 Jun 24;1:5-18.

28. Bansal SS, Goel M, Aqil F, Vadhanam MV, Gupta RC. Advanced drug delivery systems of curcumin for cancer chemoprevention. Cancer prevention research. 2011 Aug 1;4(8):1158-71.
29. Kanitkar M, Gokhale K, Galande S, Bhonde RR. Novel role of curcumin in the prevention of cytokine-induced islet death in vitro and diabetogenesis in vivo. British journal of pharmacology. 2008 Nov;155(5):702-13.

30. Danafar H. Study of the composition of polycaprolactone/poly (ethylene glycol)/polycaprolactone copolymer and drug-to-polymer ratio on drug loading efficiency of curcumin to nanoparticles. Jundishapur Journal of Natural Pharmaceutical Products. 2017 Feb $28 ; 12(1)$.

31. Zabihi F, Xin N, Li S, Jia J, Cheng T, Zhao Y. Polymeric coating of fluidizing nanocurcumin via anti-solvent supercritical method for sustained release. The Journal of Supercritical Fluids. 2014 May 1;89:99-105.

32. Khalafalla RE, Müller U, Shahiduzzaman MD, Dyachenko V, Desouky AY, Alber G, Daugschies A. Effects of curcumin (diferuloylmethane) on Eimeria tenella sporozoites in vitro. Parasitology research. 2011 Apr;108(4):879-86.

33. Ranjan AP, Mukerjee A, Helson L, Gupta R, Vishwanatha JK. Efficacy of liposomal curcumin in a human pancreatic tumor xenograft model: inhibition of tumor growth and angiogenesis. Anticancer research. 2013 Sep 1;33(9):3603-9.

34. Peng S, Li Z, Zou L, Liu W, Liu C, McClements DJ. Improving curcumin solubility and bioavailability by encapsulation in saponin-coated curcumin nanoparticles prepared using a simple $\mathrm{pH}$ driven loading method. Food \& function. 2018;9(3):1829-39.

How to cite this article: Dutta A, Patil RK, Patil HC. Curcumin: its bioavailability and nanoparticle formulation: a review. Int $J$ Health Sci Res. 2021; 11(10): 228-238. DOI: https:// doi.org/10.52403/ijhsr.20211030 